\title{
Abrabam Calles
}

Abraham Colles was responsible for much of the early scientific development of surgery in Ireland and was the leading Irish surgeon of his time; indeed he is regarded by many as the greatest of them all. His wider fame rests upon the classical descriptions he gave of certain anatomical structures and of a common fracture of the radius.

He was born at Millmount near Kilkenny on July 23, 1773, being descended from a Worcestershire family, some of whom had sat in Parliament. A branch of the family had settled in Ireland and one of its members was said to have been in medical practice in Kilkenny in the early eighteenth century; his descendent, William Colles, married Mary Anne Bates of Woodbrook, County Wexford, and Abraham was their son. The father, who managed the extensive quarries of black marble he had inherited, died when the boy was only six years old but the mother gave a good education to her young children and held their affection throughout a long life of eighty-nine years. They were sent to Kilkenny Grammar School where the headmaster was the Reverend John Ellison, sometime Fellow of Trinity College, Dublin, which college Abraham, and his brother William, entered in 1790. At the same time Abraham was apprenticed for five years to Philip Woodroffe, resident surgeon at Steevens' Hospital. Early in $\mathbf{1 7 9 5}$ he took the degree of Bachelor of Arts, and later the same year was granted a licence to practice by the College of Surgeons. Whilst at Trinity he wrote a paper on "Remarks on the Condition of Political Satire" which he was advised to publish by Edmund Burke. Having received his diploma he proceeded to the medical school of Edinburgh University where, after two years of most assiduous work and frugal living, he gained the degree of Doctor of Medicine. From Edinburgh he journeyed to London, walking the whole distance of $\mathbf{4 0 0}$ miles. He attended some of its hospitals and at Guy's came into contact with Astley Cooper, whom he assisted in making the dissections which were to illustrate Cooper's monograph on hernia.

Colles returned to Dublin towards the end of the year 1797 and became attached to the Sick Dispensary in Meath Street, a Charity which had been established a few years before by the Society of Friends. The duties included home visiting in the slums of the city. He had not to wait long before receiving a hospital appointment but meanwhile this experience of medical practice among the sick poor, and acquaintance with their environment, was of great value before embarking upon the surgical career for which he was trained. On July 26, 1799, he was elected resident surgeon at Steevens' Hospital in succession to his former chief, Philip Woodroffe. At this same hospital he had served his apprenticeship and, having broadened his experience at other British schools, in Edinburgh and in London, and returned home proud of the friendship of Astley Cooper, it was at this hospital that he was destined to spend the rest of his surgical life. He was only twenty-six years of age and it was an important appointment, for he became administrative head of one of the leading hospitals of Ireland with complete charge of one-third of the surgical beds, and was also free to engage in private practice, to teach and to receive apprentices. Furthermore, on the attainment of this post he was elected a Member of the Royal College of Surgeons in Ireland, which at that time corresponded to the Fellowship of to-day. The College was in its early years and the reason for its foundation was much the same as that of the older English College. The Irish surgeons were determined, as their brethren over the water had been, to separate themselves from the

[We are grateful to the Chairman of Steevens' Hospital, Dublin, for permission to reproduce the portrait of Abraham Colles; and to Professor Rae, Registrar of the Royal College of Surgeons in Ireland, for his aid. We acknowledge with thanks the most efficient service and excellent photography of Independent Newspapers Ltd., Dublin, particularly since they have insisted that it should be offered freely to the Journal.-EDITOR.] 


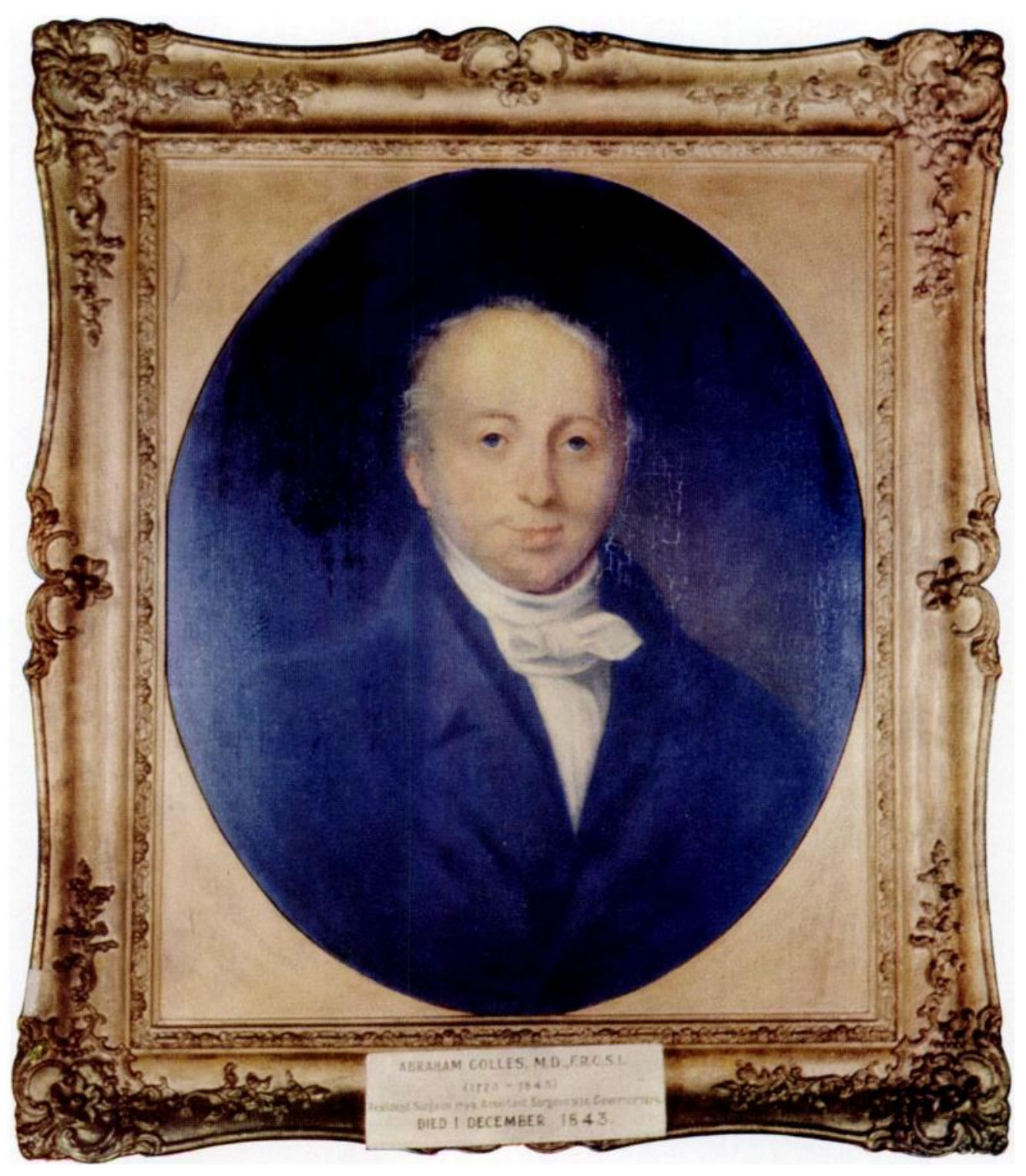

$\mathfrak{A b r a b a m ~ C o l l e s ~}$

$1773=1843$ 
barbers, and this they partly accomplished by forming the Dublin Society of Surgeons on March 29, 1780. The next step was the education of surgeons and the regulation of the profession of surgery. In the University the teaching of medicine alone was undertaken; surgery was neglected; it still had the stigma of the barber. The Society therefore began to agitate and petition for a Royal Charter "dissolving the preposterous and disgraceful union of the surgeons of Dublin with the barbers and incorporating them separately and distinctly ", into a Royal College. After a few years of opposition the Charter was granted on February 11, 1784. The next year three chairs were founded, one in anatomy including physiology, and the other two in surgery and midwifery. Thus the training of students began, but before admission to the College they had to pass a preliminary examination in Latin and Greek classics.

Colles worked with unflagging energy at Steevens' Hospital and soon became recognised as an able surgeon. He was a first-rate clinical observer and a dexterous and resourceful operator. He soon gained the respect and confidence of the Dublin surgeons, to such an extent that on January 4, 1802, when only twenty-nine years of age, he was elected President of the Royal College of Surgeons in Ireland. Two years later he was appointed Professor of Anatomy and Physiology, as well as one of the Professors of Surgery. The choice of Colles for these chairs was particularly happy. He had always been attracted to the study of anatomy, regarding it as the bedrock of surgery. He affirmed that in the training of students anatomy, in its application to surgery, should be the constant theme of the teacher. The anatomists of the Renaissance dissected and taught one system at a time-the muscles, the nerves, the blood vessels, the viscera, each separately without reference to each other; and this tradition of teaching by systems persisted until the beginning of the nineteenth century. James Macartney, Professor of Anatomy at Trinity College Dublin, who had been trained at St Bartholomew's Hospital and at the great Windmill Street School of Anatomy, appears to have been the first in the British Isles to teach topographical anatomy with emphasis on the relation of the structures of a part to each other. Colles adopted this new method of instruction and at every opportunity stressed "the practical application of anatomical researches to surgical uses." In this way he reorganised the teaching of anatomy at the College and succeeded in arousing and maintaining the interest of students by regional dissections, so that they made more "rapid advances in useful knowledge" than by way of their previous study of uncorrelated systems. Furthermore, he was the first to produce a work on this new topographical approach entitled $A$ Treatise on Surgical Anatomy which was published in 1811. The book was reprinted in America in $\mathbf{1 8 2 0}$ and again in $\mathbf{1 8 3 1 .}$

By his zealous devotion to dissecting and lecturing Colles enhanced the reputation of the College. At the same time his hospital work remained unabated, but in 1813 he resigned the appointment of resident surgeon and was promoted to the visiting staff as assistant surgeon. In 1811 he tied the first stage of the right subclavian artery for a large axillary aneurism, Thomas Ramsden of St Bartholomew's Hospital having tied the third stage of the artery for a similar condition two years previously. Each patient survived only a week because of sepsis. In his published paper describing the anatomy and details of the operation, Colles concludes: " Although this operation has not yet proved ultimately successful, I think we should not despair. The history of surgery furnishes parallel instances of operation, now generally adopted, which, in the first few trials, failed of success."

On the Distortion termed Varus or Club Foot was the title of a paper he contributed to the Dublin Hospital Reports of 1818. Two dissections of varus feet were described in detail, one of a child of five years and another of a youth of eighteen. Although he noted that "the os scaphoides was drawn inwardly from the normal head of the astragalus " yet he concluded that the oblique position of the tarsal joint, and the altered form of the astragalus were the primary causes of the distortion; from which it would appear that he either did not accept or did not fully appreciate the well-known dictum of Scarpa in his summary of the anatomy

VOL. 32 B, NO. 1, FEBRUARY 1950 
of varus which was that " none of the tarsal bones is actually dislocated; but in addition to the state of extension of the ankle joint, they undergo rotation on their axes, and the astragalus suffers less alteration of position than any of the tarsal bones." Colles cured many of these deformed feet by treating them with a club foot shoe of his own device. The shoe had a resistent sole of tin, covered with leather, laced down the middle and open at the toes. A broad strap in front of the ankle held the heel in the angle between upper and sole. A detachable angular side splint, slotted into the sole, extended along the inner side of the foot and up the inner side of the leg. Another splint, also slotted into the sole, continued along the outer side of the leg only. The splint, of which an illustration was given, corrected the equinus deformity and promoted eversion of the foot. It was applied a few weeks after birth and was continued for three months or more.

Colles was also interested in spinal disease. He adopted the teaching of Pott in his condemnation of steel stays and "other pieces of machinery" but was less convinced about the efficacy of applying caustic to each side of the gibbus. He displayed a remarkable prophetic insight with regard to the value of rest and the open air by saying: " it is absolutely necessary that the patient should be kept in the horizontal position, and this not merely for two or three months, but for a year or even two. But the caustic issues and position alone will not cure the disease of themselves; the general health, the tone of the constitution must be improved by country air, proper diet and so on; it will not be enough to send your patients to the country, if they are left shut up in a room; they must be brought out into the open air, but of course in a cot, for they are not to quit the horizontal position."

Because of the work of Colles on the anatomy of the perineum and on the common fracture of the radius his name is familiar to every student of medicine.

Colles' fascia-In the Treatise on Surgical Anatomy of 1811 Colles dealt with the anatomy of the perineum and, in particular, drew attention to the middle fascia of the urogenital triangle, the attachments of which served to confine within strict limits extravasation of urine from a ruptured urethra. He described this structure as follows: "Now proceed to dissect the perineum. Raise the skin of the perineum, extending the dissection beyond the tubera ischii to the thighs. This exposes to view a strong fascia, which, on dissection, will be found to cover the entire of the perineum, and to blend itself with the structures of the scrotum. This fascia, although on a superficial view it appears continuous with the fascia of the muscles of the thigh, will yet be found, on closer examination, to attach itself very firmly to the rami of the ischium and pubis. The texture and connexions of this fascia will serve to explain many of those phenomena attendant on the effusion of urine into the perineum, by rupture or ulceration of the posterior part of the canal of the urethra.

"First, then, you will find that this fluid, when so effused, although it forms a tumour in perineo, rarely terminates by suppuration and ulceration in this spot; being here resisted by the dense and unyielding texture of the fascia, diffusion laterally towards the thighs is prevented by the close attachment of this fascia to the rami of the pubis and ischium; while its progress forwards is favoured by a quantity of cellular substance, interposed between the surface of the perineal muscles and this fascia."

Colles' ligament is the name sometimes given to the small triangular fascia which springs from the pubic crest and ilio-pectineal line and passes upwards and inwards towards the linea alba under cover of the internal pillar of the external abdominal ring. This ligament is also described in his book on Surgical Anatomy.

Colles' fracture-At Stephen's Green on February 21, 1814, Colles wrote his classical paper, On Fracture of the Carpal Extremity of the Radius, which appeared in the Edinburgh Medical and Surgical Journal in April of that year. It was a comparatively short paper but in its accuracy, clarity and conciseness, it was admirable. It is an outstanding descriptive fragment of clinical surgery the reading of which conveys a feeling of finality in the presentation of the signs of fracture and deformity. The passage of time has altered only 
the treatment of this injury and not more than twenty years have passed since a satisfying technique has emerged. Colles was established as a great clinical surgeon by this paper. At the time he wrote it, he had not been able to verify his observations by dissection and he had not the advantage of X-rays. There is scarcely a reference to this common injury in the literature before 1814. Those who were aware of it believed that it was a dislocation of the carpus. Colles dissented from this view: "The injury to which I wish to direct the attention of surgeons, has not, as far as I know, been described by any author; indeed, the form of the carpal extremity of the radius would rather incline us to question its being liable to fracture. The absence of crepitus and of other common symptoms of fracture, together with the swelling which instantly arises in this, as in other injuries of the wrist, render the difficulty of ascertaining the real nature of the case very considerable.

"This fracture takes place at about an inch and a half above the carpal extremity of the radius, and exhibits the following appearances.

"The posterior surface of the limb presents a considerable deformity; for a depression is seen in the forearm, about an inch and a half above the end of this bone, while a considerable swelling occupies the wrist and the metacarpus. Indeed the carpus and base of the metacarpus appear to be thrown backward so much, as on first view to excite a suspicion that the carpus has been dislocated forward.

"On viewing the anterior surface of the limb, we observe a considerable fulness, as if caused by the flexor tendons being thrown forwards. The fulness extends upwards to about one-third of the length of the fore-arm, and terminates below at the upper edge of the annular ligament of the wrist. The extremity of the ulna is seen projecting towards the palm and inner edge of the limb; the degree, however, in which this projection takes place, is different in different instances. ... At last, after many unsuccessful trials, I hit upon the following simple method of examination, by which I was enabled to ascertain that the symptoms above enumerated actually arose from a fracture, seated about an inch and a half above the carpal extremity of the radius.

"Let the surgeon apply the fingers of one hand to the seat of the suspected fracture, and, locking the other hand in that of the patient, make a moderate extension, until he observes the limb restored to its natural form. As soon as this is effected, let him move the patient's hand backward and forward; and he will, at every such attempt, be sensible of a yielding of the fractured ends of the bone, and this to such a degree as must remove all doubt from his mind." Colles' Law-In 1837 Colles published a book entitled Practical Observations on the Venereal Disease and on the Use of Mercury. He strongly advocated the use of mercury in syphilis in opposition to a prevailing tendency amongst surgeons to employ less effective remedies. But in using it he maintained strict control of the patient and of the use of the drug, for his experience in clinics for venereal disease had taught him the dangers of mercurial poisoning. In a chapter dealing with syphilis in infants, he made an observation which later became known as Colles' Law: " One fact well deserving of our detention is this: that a child born of a mother who is without any obvious venereal symptoms and which, without being exposed to any infection subsequent to its birth, shows this disease when it is a few weeks old, this child will infect the most healthy nurse, whether she suckle it or merely handle and dress it; and yet this child is never known to infect its mother, even though she suckle it while it has venereal ulcers on the lips and tongue." He clearly observed the apparent immunity of the mother but could not have guessed that she already had the disease in a mild form. It was nearly seventy years later that the Spirochaeta pallida of Schaudinn was discovered and the serological test devised by Wassermann.

This work on venereal disease was his last important contribution. Failing health had compelled him to resign the professorship of surgery one year before his observation. He had already vacated the Chair of Anatomy in 1827 at a time when he was lecturing to over 250 students. He continued at Steevens' Hospital until 1841, where he had served as man and

vol. 32 B, No. 1, FEBRUARY 1950 
boy for close upon half a century and had been Consulting Surgeon to the Rotunda Hospital since 1826. In 1830 he was elected for the second time President of the Royal College of Surgeons in Ireland, and nine years later was offered a baronetcy but declined the honour. He died on December 16, 1843, and " his funeral was attended by a huge concourse of medical men, students and friends."

For the last twenty years of his life he had the most lucrative surgical practice in Dublin and this in spite of the demands of his professorship and hospital duties. He lived during most of his life at 21 Stephen's Green, having married Sophia, daughter of the Rev. Jonathan Cope, Rector of Ahaseragh, County Galway. They had ten children; the eldest son, William, became Regius Professor of Surgery at Trinity College and was elected President of the Royal College of Surgeons in Ireland in 1863. Colles was an indefatigable worker all his life; he was often in his dissecting room before six o'clock in the morning, and at Steevens' Hospital at seven. As a lecturer he was always earnest, lively and sometimes humorous. A critical contemporary speaks of him as "without many books, and paying less attention to their contents, he is still the laborious, shrewd, observing, matter-of-fact and practical surgeon. As an operator he has many equals, and some superiors; but in advice, from long experience and a peculiar tact in discovering the hidden causes of disease, he has scarcely a rival." $\mathrm{He}$ was a close and accurate observer; nothing escaped him; yet he was cautious in interpreting what he observed, and this quality of mind often prevented him from speculative reasoning about the behaviour of disease. He made a substantial contribution to knowledge, added to which the " outstanding feature of his character was his strict honesty both in thought and deed, and he followed consistently the highest code of professional honour." And what he had to say was communicated in such a simple and easy style that the reading of his papers gives a peculiar pleasure even to-day.

On his retirement in 1836, the College presented an address to him which said "It is the unanimous feeling of the College that the exemplary and efficient manner in which you have filled this Chair for thirty-two years, has been a principal cause of the success and consequent high character of the School of Surgery in this country." No other surgeon of Ireland holds so secure a place in the history of British surgery.

ARTHUR ROCYN JONES

I gratefully acknowledge the help kindly given me by $\mathrm{Mr} \mathrm{H}$. Osmond-Clarke, C.B.E., and $\mathrm{Mr}$ Terence McSweeney.

\section{REFERENCES}

Anonymous (1915): Abraham Colles. British Journal of Surgery, 2, 351.

Bettany, G. T. (1887): Dictionary of National Biography, 11, 333.

Colles, Abraham (1817): On the distortion termed Varus, or Club Feet. Dublin Hospital Reports, 17. Colles, Abraham (1844): Lectures on the Theory and Practice of Surgery. Edited by Simon McCoy. Dublin: S. J. Machen.

Kelly, E. C. (1940): Medical Classics, 4, 1027.

KirkPatrick, T. P. (1931): Irish Journal of Medical Science, 66, 241.

Widdess, J. D. H. (1949): An Account of the Schools of Surgery, Royal College of Surgeons, Dublin, 1798-1948. Edinburgh: E. \& S. Livingstone, Ltd. 